\title{
Pilot Implementation of Child Psychosocial Framework in Kenya, Turkey and Brazil
}

\begin{tabular}{|r|l|}
\hline Journal: & Journal of Children's Services \\
\hline Manuscript ID & JCS-02-2019-0008.R1 \\
\hline Manuscript Type: & Research Paper \\
\hline Keywords: & $\begin{array}{l}\text { child mental health, psychosocial, service transformation, participation, } \\
\text { LMIC, Interdisciplinary }\end{array}$ \\
\hline \multicolumn{2}{|l}{} \\
\hline
\end{tabular}

\section{SCHOLARONE \\ Manuscripts}




\section{Development of Child Psychosocial Framework}

in Kenya, Turkey and Brazil

17
17
18
19
20
21
22
23
24
25
26
27
28
29
30
31
32
33
34
35
36
37
38
39
40
41
42
43
44
45
46
47
48
49
50
51
52
53
54
55
56
50




\begin{abstract}
Purpose

To develop a child psychosocial framework among stakeholders in areas of disadvantage in three low- and middle-income countries (LMIC) Kenya, Turkey and Brazil, and to capture their proposed recommendations through action plans according to this framework.

Design/methodology/approach

Workshops were facilitated with a total 54 participants from different disciplines. The framework addressed safety and child-centredness, quality of care, resilience-building in schools and communities, enhancing competencies within existing roles, counselling and psychological interventions, and access to mental health services. Stakeholders' perspectives were captured through a participatory action procedure.

\section{Findings}

The emerging 33 categories across the framework dimensions and the three sites led to four overarching and inter-linked themes. These related to: community awareness; empowerment and 'mobilization' of children, young people and families; inter-agency policy and practice; and capacity-building on skills acquisition at different levels.

Research limitations / implications

The next stage in this service research should be full implementation and evaluation in different LMIC contexts.

\title{
Practical implications
}

It is feasible to implement such a child psychosocial framework in contexts of conflict and disadvantage, and in the absence of specialist mental health services. Active stakeholder engagement and co-production should be central to the next phase of service transformation in LMIC.

Originality / value 
This study captured the views and experiences of stakeholders in LMIC areas of disadvantage, and demonstrated their readiness to establish interdisciplinary networks and to re-focus existing services.

Key words: child, mental health, psychosocial, service transformation, participatory, LMIC 


\section{Introduction}

Improving children's mental health is gaining increasing recognition and importance globally, including in low- and middle-income countries (LMIC). Its provision is, however, constrained by several established barriers such as negative attitudes and stigma, different conceptualizations of mental health and illness, limited capacity in workforce numbers and skills, and lack of culturally appropriate and contextualized interventions (Betancourt and Williams, 2008; Jordans et al., 2010). High levels of risk through human- and nature-induced conflict, and socioeconomic disadvantage are usually compounded by the lack of resources (Tol et al., 2010; Hussein et al., 2012; Reed et al, 2012).

To begin to address these gaps through emerging evidence, there is current attention on maximizing LMIC strengths by intervening early through schools and communities, upskilling parents and paraprofessionals, and using new technologies (Fazel et al, 2014; Patel and Rahman, 2015). It is widely accepted that these challenges can only be addressed through co-production with and ownership by communities, cultural adaptation and appropriateness of interventions, and their integration into existing systems that variably involve provision by non-governmental organizations (NGOs) (Lund et al., 2016). Despite agreement on such principles, stakeholder engagement and active input is still lacking (Getanda et al., 2017).

In terms of service models in LMIC, international bodies propose a stepped care approach and scalability of psychosocial interventions (Beaglehole et al., 2008; WHO, 2008 and 2014). However, despite the influence and gradual embedment of the children's rights agenda (UNCRC, 1989), and the acknowledgement of the importance of providing mental health and psychosocial support in humanitarian, post-conflict and fragile contexts (WHO, 2012; UN, 2014), guidelines are still largely based on adult mental health criteria and on limited 
evidence (WHO, 2010; UNHCR, 2013). Recent initiatives have begun to address the psychosocial needs of vulnerable groups such as orphaned and other disadvantaged children (REPSSI, 2018), some of which have been adapted in different local contexts such as in Kenya (MLSS\&S, 2015). However, to date there are no evidence-based guidelines on how to transform service provision in LMIC (Klasen and Crombag, 2013; Vostanis, 2017).

Addressing the inter-linked issues of child mental health needs, service gaps and sparse expert capacity is, therefore, becoming a LMIC priority (Patel et al., Patel and Rahman, 2015). This indicates the need for the development of a service approach that maps, integrates and maximizes existing resources and community strengths according to a theory- and datadriven framework; is co-produced with local stakeholders; and is culturally acceptable. Addressing this gap underpinned the rationale for this study during the first phase of this action research process towards the eventual development of a theory- and data-driven set of guidelines on how communities and stakeholder organizations can jointly expand psychosocial provision in LMICs.

\section{Methodology}

To address this research and service gap and attend to the required processes to do so, necessitated an innovative methodological approach, incorporating person-centred ideology, a co-production framework, and creativity of method. This was informed by the implementation science framework, with the 'exploration' phase being evaluated in this study (Blasé et al., 2013). The aims of this study thus were, to:

a. Describe the early development and pilot implementation of an overarching framework in selected target areas in three LMIC: Kenya, Turkey and Brazil.

b. Capture stakeholders' perspectives in co-producing and informing an action plan. 
The specific research questions, were:

a. Could stakeholders across different sociocultural and service contexts relate to the framework, specifically to the mapping and action plans?

b. What were the similarities and differences in general thematic issues arising from the action plans in the three research sites?

Consistent with the aims of the study, and to fully achieve its person-centred and culturally appropriate goals, a creative and innovative approach to data collection and analysis were taken. In order to engage stakeholders throughout the process, a Participatory Action Research design (PAR) was adopted, as this is a research tool that enables groups collectively affected by a problem to 'participate' in the process of developing 'actions' to address that problem. In so doing, PAR enables the active engagement of community members to raise awareness of the issues, and relies on them as a source of expertise in facilitating possible solutions (Reason, 1994). The process of engagement and co-production recognized the relevance and importance of language and shared meaning, as well as emphasizing and valuing participants' voices. Consistent with this, therefore, a social constructionist personcentred theoretical framework underpinned the methods. This approach to data collection and the analytic process identifies and illuminates the constructed accounts of those directly experiencing the training (Burr, 2003).

\section{Development of child psychosocial framework}

To inform this research process, based on major theories (ecological systems Bronfenbrenner, 1979; hierarchy of needs - Maslow, 1943), and the best available evidence on child mental health needs in LMIC (Kieling et al., 2011; Patel and Rahman, 2015), we developed a conceptual framework, as part of the World Awareness for Children in Trauma 
Insert Figure 1 about here

Domain 1: Safety and child-centeredness

Meeting basic physical (water, food, shelter, sanitation) and emotional needs, ensuring physical and emotional safety, removal from conflict, clear guidelines to staff and residents on child protection and domestic violence, child protection training, adherence to national and international legislation, child-centred approaches - e.g. no punishment, child-friendly and nurturing environments, multi-purpose spaces, opportunities for engagement; and tackling stigma and negative attitudes on vulnerability such as being in care, gender, violence, or mental health (Hutchinson et al., 2015; Cameron et al., 2018).

\section{Domain 2: Quality of care}

Nurturing approaches by caregivers and practitioners, key principles of attachment theory in induction and ongoing training, nurturing - instead of regimental - ethos, positive parenting or caregiving strategies, attachment-focused strategies, and support mechanisms for caregivers such as supervision (Betancourt et al., 2017; Eruyar et al. 2018b; Howe et al., 2017). 
Domain 3: Building resilience through schools and communities

School as a central hub in the support system, emotional literacy, principles of whole school ethos, integration of family-school-community approaches, teacher and community worker/volunteer training on problem recognition and strategies, sports and creative activities within a resilience framework, peer support, mentorship, or life skills training (Jordans et al., 2010; Baum et al., 2013; Hussein and Vostanis, 2013; Mutiso et al., 2017).

Domain 4: Enhancing skills of universal practitioners and communities Adaptation of therapeutic principles and key approaches (e.g. psychoeducation, behavioural, cognitive-behavioural or creative therapies) to existing roles, clarity on target groups (universal or at risk) and goals, mostly in group format, training and supervision - including awareness of limitations of the approach and potential risks, and being theory-driven and evidence-based (Cartwright et al., 2015; Rahman et al., 2008; Vostanis, 2016).

Domain 5: Counselling and psychological interventions Mechanisms of identification of children with chronic/complex mental health needs, culturally appropriate and engaging approaches, tailored but underpinned by a clear therapeutic framework, assessment and formulation skills, access to one or more key modalities (behavioural, psychodynamic, cognitive-behavioural, narrative, creative), delineation of specific short- and medium-term goals, individual or group-based modalities, training and supervision, and utilization of new technologies and training materials (Klasen and Crombag, 2013; McMullen et al., 2013; Morina et al., 2017). 
Domain 6: Access to mental health services

Direct links with existing services, care pathways, clear referral criteria, targeted use of limited resources, joint training forums, outreach or consultation clinics by mental health practitioners, interdisciplinary networks, capacity-building strategy, and training the trainers programme (WHO, 2005; Skokauskas et al., 2011).

\section{Process of delivery of child psychosocial framework}

The framework was delivered through the following phases:

In phase 1, target groups of vulnerable children were identified in three LMIC through ongoing partnerships with NGOs under the (World Awareness for Children in Trauma) programme, who had previously co-ordinated practice-focused training (Vostanis et al., 2019). In phase 2, the authors and each host NGO identified agencies operating in the target areas and in contact with the identified vulnerable groups (see below for details) from primary health, mental health, child protection and other social care, schools, special needs, community and religious organizations, care homes, NGOs, and policy makers. One senior practitioner from each identified agency was invited to a participatory workshop. Children, young people and parents (with one exception in Kenya) were not involved in this stage of delivery. In phase 3, the oneday workshops adapted an interdisciplinary stance designed so that participants interacted to learn 'with, from and about one another' to share their expertise in meeting children's psychosocial needs (WHO, 2010 p. 6; Vostanis et al., 2019). Training guidelines and a draft manual were developed by the workshop facilitators (co-authors 1 and 3) according to the framework. 
In phase 4, each workshop started with mapping of local needs, existing resources, community strengths, and readiness of stakeholders in the selected target areas. This was followed by brief presentations on the six domains of the framework. Participants were subsequently asked to co-produce action plans in each domain through small groups, and to identify realistic and staged goals in addressing service gaps. The training guidelines and manual were iteratively refined after each workshop.

\section{Settings and participants}

A strategic approach to the selection of LMIC and target groups was taken, to ensure inclusion of countries and communities within them, from across the LMIC income spectrum according to Organisation for Economic Co-operation and Development criteria (OECD, 2016). This ensured the selection of a range of vulnerabilities in middle- (Turkey, Brazil) and low-income countries (Kenya). The respective vulnerable groups within each country thus, were: street and refugee children in a large area of Istanbul, Turkey; living in 16 favelas (shanty towns or shacks) in Rio de Janeiro, Brazil; and children in a slum area following ethnic violence and internal displacement in Nakuru city, Kenya. Three workshops were conducted, with a total 54 participants in Nakuru (1st May 2018), Istanbul (23rd June 2018) and Rio de Janeiro (10th August 2018). Overall, 15 stakeholders attended the event in Turkey, 12 in Brazil and 27 in Kenya. The participants' agency and professional profiles are presented in Table 1.

Insert Table 1 about here

\section{Participatory evaluation procedure}

A participatory action research procedure was followed to capture and evaluate stakeholders' perspectives. This participant-driven procedure is increasingly used to co-address a solution 
to a problem, with participants who are marginalized or excluded from service planning and implementation, as in the case the limited child mental health service provision (Rhodes et al., 2015; Willow, 2013). Participants do not focus on merely understanding a given problem, but rather in generating collectively developed actions (Kidd and Kral, 2005). Understanding their perspectives can thus inform the development of theory of change to address service gaps.

Ethics approval was granted by the (University of Leicester Psychology) Research Ethics Committee, following written agreement by the three host agencies. Within each workshop, attendants were asked to break into small interdisciplinary groups of 5-6 participants each to discuss and come up with responses to the identified tasks, namely mapping needs and strengths, and devising action plans on each of the six framework domains. Each small group had a facilitator in the discussion, who was also responsible for collating co-produced responses in a written format (flipchart - see Photo 1 for example). A second small group member was tasked with taking field notes of the discussions, in order not to lose their meaning by only relying on written material. In Kenya, discussions were largely in English language, partly in Swahili, and all collected material was in English. In Turkey and Brazil, discussions and collected material were in Turkish and Portuguese language respectively. These were subsequently translated into English by the independent researcher (author 2) in Turkey and the host co-facilitator in Brazil.

Insert Photo 1 about here

\section{Analytic approach}


Because of the innovation of the methodology, the complexity of the evidence surrounding child mental health in LMIC, and the integration of the WACIT framework into the data collection, it was deemed appropriate to utilize template analysis to address the research questions. Underpinned by a thematic design, its emphasis is on participant meaning creation (Braun and Clarke, 2006), and provides a structural framework to create a template of categories (King, 2004). The initial template was shaped and informed by the research agenda and the existing evidence in this area. However, the template is bidirectional, in the sense that the template was further influenced by the person-centred theoretical framework and participant perspectives that were required through the participatory techniques of the methodology. In other words, the template analysis allowed the research agenda and evidence-base to influence the initial template design.

This further encourages the refinement and redevelopment of the template through the iterative inclusion of participant views to map and overlap the relevant concepts and issues. Furthermore, the refining of the template allows the data to intersect with the workshop materials and fieldnotes, i.e. the aspects of data collection which are seen to inform the analytic messages (Johnson et al., 2013). The development of the template was co-developed within the team, as first order categories were identified by positioning them across the three mapping and six action plan domains (Table 2). Subsequently, these were subjected to second order analysis to establish the identified final themes across domains and countries, thus settle the final template.

\section{Results}

Template analysis was thus utilized to identify common perspectives (categories) across the mapping exercise, followed by recommended solutions (action plans) put forward by the 54 
stakeholders from the three LMIC. Overall, 11 mapping and 22 action plans categories were identified at the first analytic stage: 
Insert Table 2 about here

\section{Mapping}

The mapping analysis was structured along three components, i.e. vision, participants' roles and current resources.

\section{Vision}

Participants across all three sites set a broad vision in broadly improving children's lives rather than only focusing on mental health issues. Their encompassing priority was meeting their 'fundamental' rights, creating safe spaces, and changing policies to become more childfocused. This would enable them to improve their mental well-being, psychological resilience, 'family permanence', and school attainment. Awareness, sensitization, empowerment, and 'strengthening family and community ties' were key in this process. Their vision in service delivery included developing protection units, counselling services, and providing economic and social support. This would require re-prioritization of funds and resources for children.

\section{Own role}

Participants came from a range of discipline backgrounds. Nevertheless, they identified common functions that cut across these disciplines. They viewed themselves as bringing knowledge of the 'territory', its history and vulnerabilities, and relating those to children's needs ('relation of affection to territory'). Protection of children's rights, empowerment (through religious groups, schools and communities), and 'nurturing of children's talent' were common objectives. These could be achieved through skills like rapport and selfexpression, before addressing their needs through education and interventions. Volunteering was prominent within the Turkey workshop. 


\section{Current resources}

Human resources were defined in terms of professionals, as well as professional and community volunteers. Communities contributed through networks and associations related to resident areas, religious and cultural groups, youth, and civil societies (mostly from Brazil). Agencies were both statutory and non-governmental from health, education and social welfare, a proportion of which (e.g. primary education and basic health care) were provided for free. There was limited specification to settings such a child protection unit and remand home in Kenya, without any reference to child mental health services.

\section{Action plans along the six framework domains}

\section{Safety and child-centeredness}

Tackling safety and attitudes were strongly linked with supporting policy and implementation to enhance child safeguarding. Four themes, therefore, emerged as proposed actions for this domain. The improvement of physical and emotional safety was consistent, but especially prominent in Brazil, and the context of rising criminality and gang violence in Rio de Janeiro and the participating favela areas. 'Square revitalization' and 'increase of residence flow in the square' were specific suggestions in creating safety spaces that would enable other action plans across the remaining domains to take effect. For example, mental health practitioners had stopped running clinics in this area after the increase in inner-city violence.

Enhancing public and professional awareness on child safety, whilst tackling negative attitudes (mainly stigma and fear) towards both violence and mental illness were commonly suggested across the three sites. Seeking role models in the community and spiritual teaching were proposed engagement strategies. These could not operate in silo, but would need to be supported by relevant policy and legislation. In turn, policy could only be implemented by the 
release of funds by the respective governments, lobbying for which was one suggested mechanism. Implementation of policy would consequently require training for all professionals in contact with children such as teachers, in recognizing signs and acting on child protection grounds. Skills in communicating with vulnerable children was central to participants' recommendations. Training methods should utilize new technologies. These could boost face-to-face training through digital modules and web-based materials, provide individual or group supervision, raise awareness through social media, and enhance service user engagement through mobile apps (Hilty and Yellowlees, 2015).

\section{Quality of care}

Participants shared three inter-linked recommended categories in relation to supporting parents and other caregivers such as care homes staff. Awareness, mainly in the form of psychoeducation, was viewed as the first step. This was suggested to include positive parenting, the importance of secure attachment relationships, and the understanding and recognition of emerging mental health signs. Awareness was followed by the urge to mobilize and engage families through co-operation with organizations such as NGOs, health and social care agencies. Such mobilization was viewed as prominent in help-seeking and accessing appropriate services. A specific type of recommended psychosocial support was through groups for parents and other caregivers. In the case of Turkey, where an excessive number of refugee families with complex needs have been hosted in recent years across the country, psychosocial input for Syrian parents was suggested by using less stigmatizing and more engaging strategies, and by integrating with practical supports and life skills training such as sewing classes for mothers.

\section{Building resilience through schools and communities}


Increasing child mental health awareness was again considered paramount to any school- or community-based interventions. Participants identified public and religious institutions as key conduits in this process. Churches in Kenya and mosques in Turkey were viewed as prominent in accessing and engaging communities, especially in areas of disadvantage. Although there was some overlap with domain 1 in providing safe and child-centred environments, participants also considered improvements in the functionality of schools and community settings that would enable the delivery of interventions. For example, building and protecting playgrounds was particularly voiced by participants in the highly deprived and crime-affected inner-city favelas of Rio de Janeiro. Supporting and inclusive educational policies should result in reviewing the school curriculum, monitoring implementation, accessing evidence, and targeting emerging priorities such as school violence. The importance of inter-agency working was acknowledged as an opportunity for schools to integrate with local agencies and communities. However, no specific examples of interventions were put forward in this domain.

\section{Enhancing skills of universal practitioners and communities}

Capacity-building was mentioned across all domains, with overlap on teacher and peer training with the previous domain on schools and communities. Those in constant contact with vulnerable families such as family or primary care physicians were specifically mentioned. The importance of continuous training, preferably through collaboration between stakeholders, was highlighted across all three groups. Its objectives included understanding the effect of trauma on children's mental health, recognition of common mental health problems, and how to direct families to appropriate services. Teacher training was the most prominent action to be taken in Turkey, where nearly one and a half million refugee children started attending public schools after the recent establishment of integrated educational (EU 
Delegation to Turkey, 2017). Consequently, teachers, as well as volunteers and other professionals, should acquire skills in helping refugee children with both war trauma-related and current adjustment (poverty, language and acculturation) difficulties. Attention was given to the retention of professionals through empowerment, motivation, and better employment terms. Competencies should address community needs such as developing social diversity and coping strategies, with particular focus on minority groups like black women in Brazil.

\section{Counselling and psychological interventions}

Interestingly, awareness was again viewed as a pre-requisite to families seeking and accepting psychological help. A range of approaches were suggested to 'demystify' counselling such as through leaflets, online information, TV series, presentations in communal spaces, and general 'visibility'. These strategies should be followed by professionalization of counselling through a legal framework, incorporation in existing professional curricula, and identification of additional resources. Finally, counselling and other psychological interventions would become more accessible by integrating them to existing services. No specific intervention modalities were put forward.

\section{Access to mental health services}

Promoting joint care pathways by linking existing child and adult services to the limited mental health provision emerged as a common action plan at all sites. This would, however, require co-operation and integration between statutory and non-governmental sectors across health, welfare and education. Networking and workshops could facilitate the establishment of such partnerships. These two approaches would partially address current gaps, but would still require additional awareness campaigns on how they could be accessed by communities ('mobilization'). Access would be enhanced by providing mental health services within 
community hubs, for example at mosques. The dearth of mental health facilities required 'political influence' in identifying a new and designated 'budget allocation'.

In the second order of analysis, the 11 mapping and 33 action plans themes resulted in the following core categories that created the final template (Figure 2):

- Awareness

- Empowerment

- Inter-agency working

- Capacity-building.

Insert Figure 2 about here

\section{Discussion}

Meeting the psychosocial needs of children and young people in LMIC is faced with various barriers; namely lack of policy, stigma, cultural adaptation of interventions; and limited resources in terms of core staff numbers and skills. Recent years have, however, seen increasing attention in developing guidelines on how local strengths can be integrated with therapeutic and service models (Callam, 2017; UN, 2014). These are often framed in the context of related Sustainable Development Goals (Dornan, 2017). This study was positioned within such a policy, service and research gap. The objective was the development and implementation of such a framework in three LMIC settings operating in different systems, albeit within similar parameters of disadvantage, vulnerability and low service access; and the pilot evaluation of participants' utilization of this approach by using participatory action research methods. 
The feasibility of delivering the framework was supported by the uptake across the sites. This required substantial partnership-building over the precipitating period, through one agency (all were NGOs in this study) that acted as host and co-facilitator with the external trainers. The range of community and professional roles of the participants (Table 1) indicates a positive stance towards interdisciplinary training and working, with the latter also being supported by the data. This is consistent with the findings of an earlier study on practicefocused training in child mental health across six LMIC (Vostanis et al., 2019).

Overall, the four themes emerged both across and within countries, i.e. across the framework dimensions and activities, and interdisciplinary groups. Awareness for communities and professionals alike was viewed as an essential step in shifting attitudes before actively enhancing child protection, family and caregiver supports, and building children's resilience through school- and community-based interventions. Although specific approaches of enhancing awareness were beyond the remit of this developmental phase, key principles were endorsed and successfully applied in previous studies such as respect of and integration with traditional cultural beliefs and being community-led (Campbell-Hall et al., 2010). These principles are closely linked with the second theme of empowering children, young people, parents and communities in shaping up interventions and services at all levels, so that these are viewed as accessible, engaging and non-stigmatizing (Losa and Effat, 2017).

Such user 'mobilization' (as referred to by participants) and co-production should be mirrored at policy and service level through inter-sector legislation and inter-agency working. Participants acknowledged this significance in several ways, i.e. by paving the way for interventions or supporting existing ones, securing new and designated funding, maximizing resources, and ultimately meeting vulnerable children's multiple and complex psychosocial 
needs individually, within their home, school and community (Vostanis, 2017). Stakeholders highlighted the importance of agreeing joint care pathways between existing agencies. Interestingly, in a recent study with different stakeholder groups (young people, parents, teachers, professionals and community leads) in Kenya, the overarching finding was that meeting children's and young people's mental health needs was 'everybody's responsibility' (Tamburrino et al., 2019).

There was wide reference to the importance of capacity-building through different strategies, again across all dimensions of the framework. These related to both community volunteers or peer mentors and interdisciplinary professionals, rather than in only targeting specialist mental health practitioners. Participants wished to see continuous rather ad hoc training, focus on recognition of common child mental health problems and interventions within their existing agency remit, and support mechanisms to retain staff as they acquired new competencies. There were no recommended actions on specific therapeutic modalities or interventions, maybe because this was considered premature at this stage, or because this required parallel training to enable stakeholders to make informed decisions on their cultural acceptability, indications, evidence-base and cost-effectiveness. In general, categories and themes did not refer to a specific local or national context. Some exceptions, or rather applications of stated principles, related to concerns and priorities such as the refugee crisis in Turkey and the increase in urban violence in Brazil.

This early developmental research was faced with several limitations, which constrain the generalizability of the findings, while also pointing out requirements for further research. As each site was selected through a priori partnership, neither their population nor their existing agencies necessarily share the same characteristics with other regions in their country. The 
term 'LMIC' is itself too broad and heterogeneous, although it does denote the common lack of adequately developed mental health services. Children and young people were not involved in the workshops, which would necessitate additional strategies to meaningfully engage them, especially if they came from disadvantaged backgrounds such as care homes and slum areas. Nevertheless, future research could build upon the template created to integrate children's and young people's voices in exploring how these map onto the issues perceived by adults. Overall, stakeholders across all sites articulated a vision in improving children's life circumstances, rather than exclusively focus on their mental health. This may have been a hierarchical approach in considering their basic and broader needs before delving into specific mental health issues (Maslow, 1943). It may have also highlighted the importance of delivering the training over a longer period of time, thus enabling participants to process, translate and adapt their learning and resulting action plans to children's mental health.

As all host agencies were NGOs, it is possible that additional difficulties may have been faced in working through statutory agencies which, however, would be essential in the establishment of sustainable local networks. This pilot study was implemented at one timepoint, it was thus not possible to undertake a more meaningful mapping analysis and to invite all important stakeholders. The next research phase should, therefore, extend the period of study to capture the implementation of action plans, co-production of indicators of impact, monitoring of those indicators, and evaluation of barriers and facilitators. Within the implementation science framework, this should include the installation of the intervention; the development of a logic model; and its implementation and evaluation (Fixsen et al., 2013). 
In conclusion, there are several encouraging messages from the findings. This service framework was developed and implemented in difficult circumstances, often in the vacuum of statutory resources, and during (Brazil) or post-conflict (Kenya). The participatory process achieved wide interdisciplinary engagement, and captured the voices of previously isolated or excluded communities and agencies. Participants articulated consistent and inter-linked themes on the importance of awareness, community and user empowerment, inter-agency working and capacity-building. Consequently, they provided a baseline for the refinement of the framework, and its implementation and evaluation over a longer period, with the objective of developing evidence-based guidelines. 


\section{References}

Baum, N., Cardozo, B.L., Pat-Horenczyk, R., Ziv, Y., Blanton, C., Reza, A., Weltman, A., Brom, D. (2013), “Training teachers to build resilience in children in the aftermath of war: A cluster randomized trial", Child and Youth Care Forum, 42, pp. 339-350.

Beaglehole, R., Epping-Jordan, J., Patel, V., Chopra, M., Ebrahim, S., Kidd, M., Haines, A. (2008), "Improving the prevention and management of chronic disease in LMIC: A priority for primary care”, Lancet, 372, pp. 940-949.

Betancourt, T., Ng, L., Kirk, C., Brennan, R., Beardslee, W., Stulac, S., Mushashi, C., Nduwimana, E., Mukunzi, S., Nyiranda, B., Kalisa, G., Rwabukwisi, C., Sezibera, V. (2017), "Family-based promotion of mental health in children affected by HIV: A pilot randomized controlled trial", Journal of Child Psychology and Psychiatry, 58, pp. 922-930.

Betancourt, T., Williams, T. (2008), "Building an evidence-base on mental healthinterventions for children affected by armed conflict", Intervention, 6, pp. 39-56.

Blasé, K., van Dyke, M., Fixsen, D. (2013), Stages of Implementation Analysis, University of North Carolina, Chapel Hill.

Braun, V., Clarke, V. (2006), "Using thematic analysis in psychology", Qualitative Research in Psychology, 3, pp. 77-101.

Bronfenbrenner, U. (1979), The Ecology of Human Development: Experiments by Nature and Design, Harvard University Press, Cambridge, MA. 
Burr, V. (2003), Social Constructionism (2nd ed.), Routledge, London.

Calam, R. (2017), "Public health implications and risks for children and families resettled after exposure to armed conflict and displacement", Scandinavian Journal of Public Health, 45, pp. 209-211.

Cartwright, K., El-Khani, A., Subryan, A., Calam, R. (2015), "Establishing the feasibility of assessing the mental health of children displaced by the Syrian conflict", Global Mental Health, 2 (e8) doi:10.1017/gmh.2015.3

Cameron, C., O’Leary, P.J., Lakhani, A., Osborne, J., de Souza, L., Hope, K., Naimi, M., Khan, H., Jawad, Q., Majidi, J. (2018), “Violence against children in Afghanistan: Community perspectives", Journal of Interpersonal Violence doi: 10.1177/0886260518760610

Campbell-Hall, V., Peterson, I., Bhana, A., Mjadu, S., Hosegood, V., Flisher, H. (2010), "Collaboration between traditional practitioners and primary care staff in South Africa: Developing a workable partnership for community mental health services", Transcultural Psychiatry, 47, pp. 610-628.

Dornan, P. (2017), “Children, poverty and Sustainable Development Goals", Children and Society, 31, pp. 157-165.

Eruyar, S., Huemer, J., Vostanis, P. (2018a), "How should refugee services respond to the refugee crisis?", Child and Adolescent Mental Health, 23, pp. 303-312. 
Eruyar, S., Maltby, J., Vostanis, P. (2018b), “Mental health problems of Syrian refugee children: The role of parental factors", European Child and Adolescent Psychiatry, 27, pp. 401-409.

EU Delegation to Turkey (2017, June 10). EU and Turkish Ministry of National Education launch $€ 300$ million project to improve Syrian children's access to education. Retrieved from https://www.avrupa.info.tr/en/pr/eu-and-turkish-ministry-national-education-launch-eu300million-project-improve-syrian-childrens [Accessed April 2019]

Fazel, M., Patel, V., Thomas, S., Tol, W. (2014), "School mental health interventions in lowincome and middle-income countries", The Lancet Psychiatry, 1, pp. 388-398.

Fixsen, D., Blasé, K., Naoom, S., Muda, M. (2015), Implementation Drivers: Assessing Best Practices, University of North Carolina, Chapel Hill.

Getanda, E., Vostanis, P., O’Reilly, M. (2017), “Exploring the challenges in meeting child mental health needs through community engagement in Kenya”, Child and Adolescent Mental Health, 22, pp. 201-208.

Hilty, D., Yellowlees, P. (2015), “Collaborative mental health services using multiple technologies”. JAACA Psychiatry, 54, pp. 245-246.

Howe, T., Knox, M., Altafim, E.P., Linhares, M.B., Nishizawa, N., Fu, T.J., Camargo, A.L., Ormeno, G.R., Marques, T., Barrios, L., Pereira, A. (2017), “International child abuse prevention: Insights from ACT", Child and Adolescent Mental Health, 22, pp. 194-200. 
Hussein, S., Bankart, J., Vostanis, P. (2012), “School-based survey of psychiatric disorders among Pakistani children: A feasibility study”, International Psychiatry, 10, pp. 15-17.

Hussein, S., Vostanis, P. (2013), “Teacher training intervention for early identification of common child mental health problems in Pakistan", Emotional and Behavioural Difficulties, 18, pp. 284-296.

Hutchinson, A., O’Leary, P., Squire, J., Hope, K. (2015), “Child protection in Islamic contexts: Identifying culture and religious appropriate mechanisms and processes using a roundtable methodology", Child Abuse Review, 24, pp. 395-408.

Johnson, V., Nurick, R., Baker, K., Shivakotee, R. (2013), Children and Young People's Participation (CYPP) Training Workshop Guide, Child Hope, London.

Jordans, M., Tol, W., Komproe, I., Susanty, D., Vallipuram, A., Ntamatumba, P., \& de Jong, J. (2010), "Development of a multi-layered psychosocial care system for children in areas of political violence", International Journal of Mental Health Systems, 4, 15 doi: $10.1186 / 1752-4458-4-15$

Kidd, S., Kral, M. (2005), "Practicing participatory action research", Journal of Counselling Psychology, 52, pp. 187-195.

Kieling, C., Baker-Henningham, H., Belfer, M., Conti, G., Ertem, I., Omigbodun, O., Agusto Rohde, L., Srinath, S., Ulkuer, N., Rahman, A. (2011), “Child and adolescent mental health 
worldwide", The Lancet, 378, pp. 1515-25.

King, N. (2004), "Using templates in the thematic analysis of text", in Cassell, C. and Symon, G. (Eds), Essential Guide to Qualitative Methods in Organisational Research, Sage, London, pp. $256-270$.

Klasen, H., Crombag, A. (2013), "What works where? A systematic review of child and adolescent mental health interventions for LMIC", Social Psychiatry and Psychiatric Epidemiology, 48, pp. 595-611.

Losa, N., Effat, R. (2017), "Service users and carers in low- and middle-income countries", British Journal of Psychiatry International, 14, pp. 4-6.

Lund, C., Tomlinson, M., Patel, V. (2016), “Integrating mental health into primary care in low- and middle-income countries", British Journal of Psychiatry, 208 (s56) s1-s3; doi:10.1192/bjp.bp.114.153668

Maslow, A. H. (1943), “A theory of human motivation”, Psychological Review, 50, pp. 370396.

McMullen, J., O’Callaghan, P., Shannon, C., Black, A., Eakin, J. (2013), “Group traumafocused CBT with former child soldiers and other war-affected boys in the DR Congo", Journal of Child Psychology and Psychiatry, 54, pp. 1231-1241. 
Ministry of Labour Social Security and Services (2015), National Psychosocial Support

Guidelines for Orphans And Vulnerable Children In Kenya.

https://www.usaidassist.org/sites/default/files/pss_guidelines_004.pdf [Accessed April 2019]

Morina, N., Malek, M., Nickerson, A., Bryant, R. (2017), "Psychological interventions for PTSD and depression in youg survivors of mass violence in low- and middle-income countries: Meta-analysis”, British Journal of Psychiatry, 210, pp. 247-254.

Mutiso, V., Tele, A., Musyimi, C., Gitonga, I., Musau, A., Ndetei, D. (2017), “Effectiveness of life skills education and psychoeducation on emotional and behavioural problems among adolescents in institutional care in Kenya: A longitudinal study", Child and Adolescent Mental Health, 23, pp. 351-358.

OECD - Organization for Economic Co-operation and Development (2016), Country Risk Classification. http://www.oecd.org/tad/xcred/crc.htm [Accessed April 2019]

Patel, V., Chowdhary, N., Rahman, A., Vardeli, H. (2011), "Improving access to psychological treatments: Lessons from developing countries", Behaviour Research and Therapy, 9, pp. 523-528.

Patel, V., Rahman, A. (2015), “An agenda for child mental health”, Child and Adolescent Mental Health, 20, pp. 3-4.

Rahman, A., Malik, A., Sikauder, S., Roberts, C., Creed, F. (2008), “Cognitive-behavioural therapy-based intervention by community health workers for mothers with depression and their 
infants in rural Pakistan: A cluster RCT”, The Lancet, 372, pp. 13-19.

Reason, P. (1994), "Human inquiry as discipline and practice", in Reason, P. (Ed), Participation in Human Inquiry, Sage, Thousand Oaks, CA, pp. 40-56.

Regional Psychosocial Support Initiative (2018), Research Brief 2: Prevalence of Mental Health Challenges among Vulnerable Rural Zambian Children. http://www.repssi.org/Att.aspx?fn=c52a2c62-ae74-4cbb-98e0-ce41d311c5d2.pdf [Accessed April 2019]

Rhodes, S., Song, E., Nam, S., Choi, S., Choi, S. (2015), "Identifying and intervening on barriers of healthcare access among members of a small community in the southern USA", Patient Education and Counselling, 98, pp. 484-491.

Skokauskas, N., Belfer, M. (2011) “Global child mental health: What can we learn from these countries with limited financial resources?”, International Psychiatry 8, pp. 45-47.

Tamburino, I., Getanda, E., O’Reilly, M., Vostanis, P. (2018), “Everybody’s responsibility: Conceptualisation of youth mental health in Kenya", Journal of Child Health Care doi: $10.1177 / 1367493518814918$

Tol, W., Komproe, I., Jordans, M., Gross, A., Susanty, D., Macy, R., de Jong, J. (2010), Mediators and moderators of a psychosocial intervention for children affected by politicial violence, "Journal of Consulting and Clinical Psychology", 78, pp. 818-828. 
Vostanis, P. (2016), A Practical Guide to Helping Children and Young People who Experience Trauma, Speechmark, London.

Vostanis, P. (2017), “Global child mental health: Emerging challenges and opportunities”, Child and Adolescent Mental Health, 22, pp. 177-178.

\author{
Vostanis, P., Maltby, J., Duncan, C., O’Reilly, M. (2018), “Stakeholder perspectives on \\ children's psychosocial needs in six low- and middle-income countries", Children and \\ Society, 32, pp. 457-469.
}

Vostanis, P., O’Reilly, M., Duncan, C., Maltby, J., Anderson, E. (2019), “Interprofessional training for resilience-building for children who experience trauma: Stakeholders' views from six low- and middle-income countries", Journal of Interprofessional Care, 33, pp. 143-152.

\author{
World Awareness for Children in Trauma (WACIT) www.wacit.org \\ [Accessed April 2019] \\ United Nations (2014), Mental Health Matters: Social Inclusion of Youth with Mental Health \\ Conditions, UN: New York.
}

UNHCR (2013), Operational Guidance: Mental Health and Psychosocial Support Programming for Refugee Operations, UNHCR: Geneva.

Willow, C. (2013), Involved by Right: Effective Participation of Children and Young People 
in Alternative Care Settings, Borough of Kensington and Chelsea, London.

World Health Organization (2005), Atlas: Mental Health Resources in the World, WHO, Geneva.

World Health Organization (2008), Mental Health Action Gap Programme: Scaling up Care for Mental, Neurological and Substance Use Disorders, WHO, Geneva.

World Health Organization (2010), Framework for Action on Interprofessional Education and Collaborative Practice, WHO, Geneva.

World Health Organization (2012), Adolescent Mental Health, WHO, Geneva.

World Health Organization (2014), Integrating the Response to Mental Disorders and other Chronic Diseases in Healthcare Systems, WHO, Geneva. 


\section{Table 1}

Participants' remit $(n=54)$

\begin{tabular}{|c|c|c|c|}
\hline & Kenya & Turkey & Brazil \\
\hline Teacher & 4 & 1 & $8^{*}$ \\
\hline Counsellor & 4 & 1 & $\mathrm{X}$ \\
\hline Counselling Teacher & 3 & 1 & $X$ \\
\hline Academic & 3 & 1 & $\mathrm{X}$ \\
\hline NGO Manager / & 2 & 2 & 4 \\
\hline Co-Ordinator & & & \\
\hline Volunteer & $\mathrm{X}$ & 3 & 3 \\
\hline Lawyer & 2 & $X$ & $X$ \\
\hline Police Officer & 3 & $\mathrm{X}$ & $\mathrm{X}$ \\
\hline Pastor/Religious Leader & 3 & $\mathrm{X}$ & $\mathrm{X}$ \\
\hline Health Worker/Doctor & 1 & 1 & $\mathrm{X}$ \\
\hline Psychologist & 1 & 2 & $\mathrm{X}$ \\
\hline Parent & 1 & $\mathrm{X}$ & $\mathrm{X}$ \\
\hline Total & 27 & 12 & 15 \\
\hline
\end{tabular}

*3 teachers, 2 head teachers (1 mainstream school and 1 kindergarten), 1 teacher/antiviolence educator, 1 civil rights educator, 1 teacher student 
Table 2

Mapping analysis and action plans categories along the six framework domains

\section{Mapping}

Vision

Promoting children's rights and safety

Well-being and psychological resilience

Awareness and empowerment

Service improvement

Participants' roles

Knowledge of territory

Protection and empowerment

Therapeutic skills

Education and interventions

Current resources

Human resources

Community groups

Agencies (statutory and NGOs)

Action plans

Safety and child-centeredness

Improving physical and emotional safety

Increasing awareness

Supporting policy and legislation

Skills in communication and recognition

Quality of care

Psychoeducation

Family engagement and mobilization

Support groups for caregivers

Building resilience through school and community

Raising awareness in the community through public and religious institutions

Improving functionality of environments

Educational policies

Inter-agency working

Enhancing skills of universal practitioners and communities

Continuing training on impact of trauma and symptom recognition

Staff retention

Targeted to vulnerable groups (e.g. refugee or minorities)

Community skills

Counselling and psychological interventions

Demystification through awareness

Professionalization

Integration with other services

Access to child mental health services

Joint care pathways

Inter-sector working

Family engagement

Resource allocation 


\section{Figure 1}

\section{(Anonymized) child psychosocial framework}

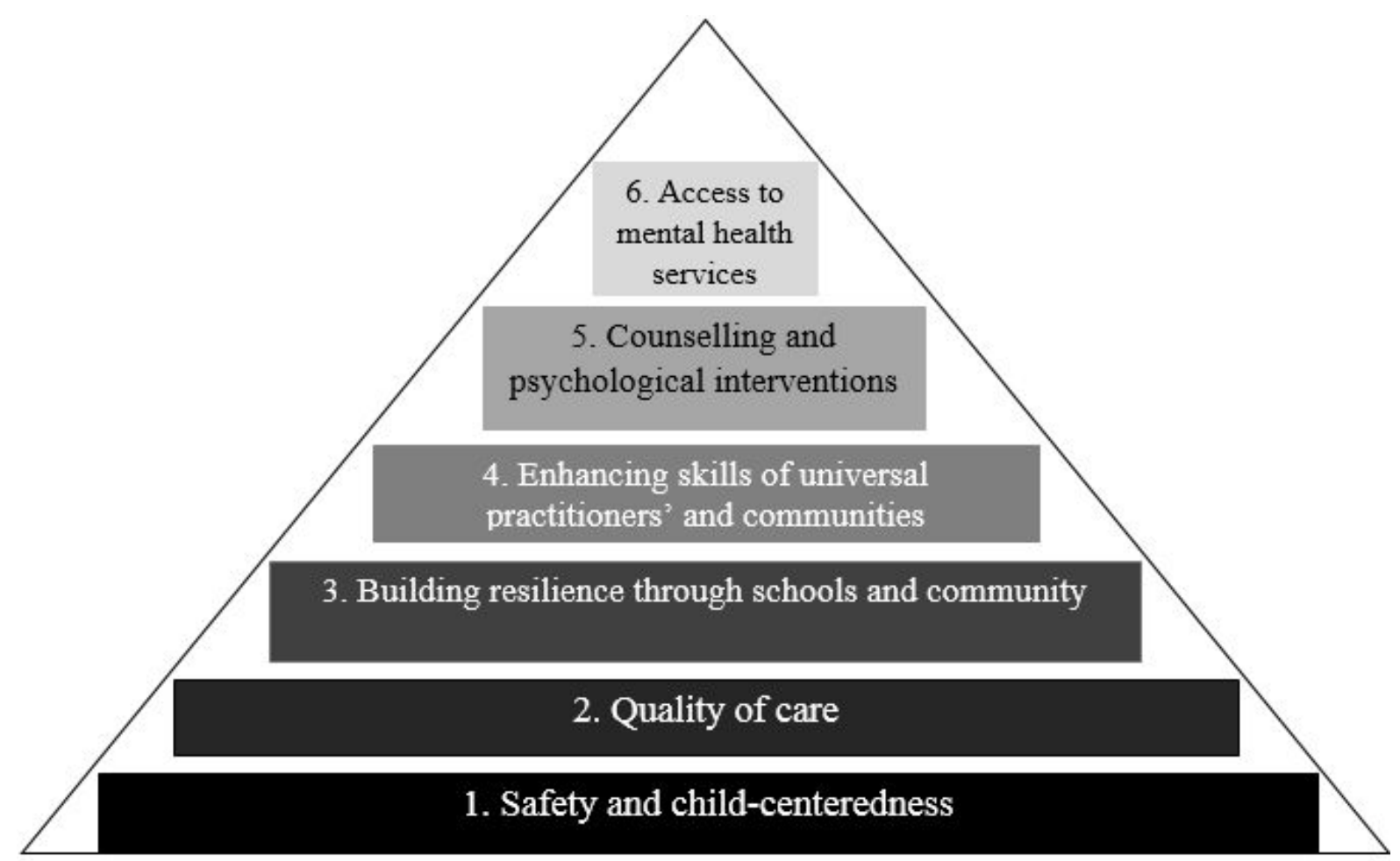


Figure 2

Final thematic template

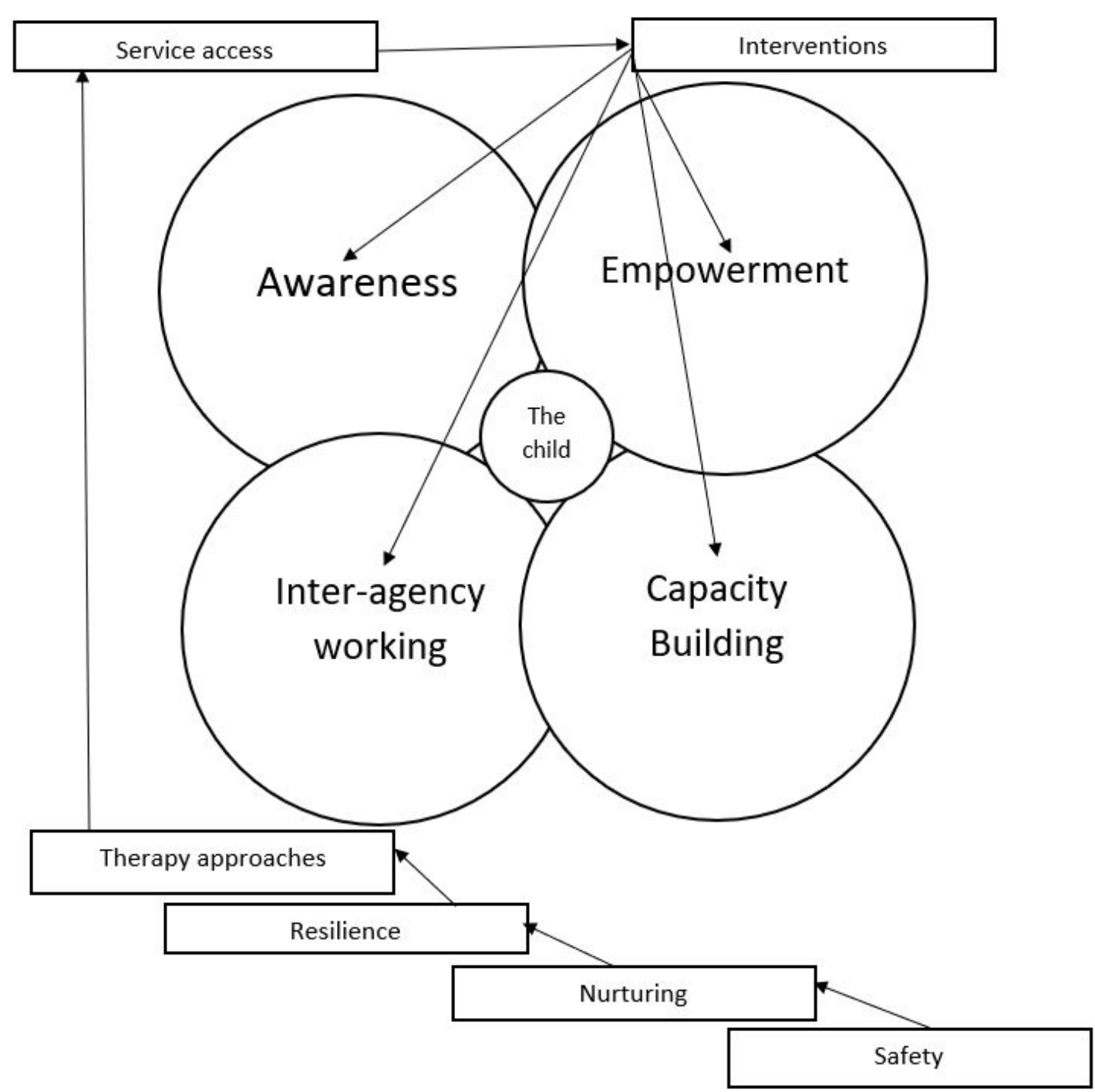


Page 37 of 42

Journal of Children's Services

1
2
3
4
5
6
7
8
9
1
1
1
1
1
1
1
1
1
1
2
2
2
2
2
2
4
2
4
4
4
5
5
5
5
5
3
5
3
3
3
3
3
3
3
3
3
3

Photo 1

Flipchart material from Kenya workshop

CHLD MENTAL HEALTH SERVICES 1. haps \& barriers

- Lack of mental faciuties for chelelion.

- stigmatization flabors

- Lack of awaroness.

- Lack of ukills on child mentas heacth.

- Lack of poutical good will cmumanggemes af June

2. Capacitie's \& strongths.

- special schools

- Health jacilites

3. prionties

- Creating nwaronoss

- scting dp Health instintions (mentar).

- Budgot allocations (proper).

4. Actron plan.

- crominging more jacilities for mental health.VICt

- Communizy mobi lizatión.

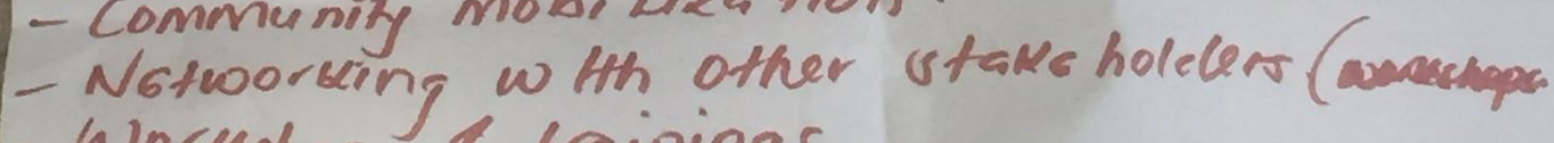

- Workshops \& frainings

- pouticar infuencing Jor funds.

37 
Table 1

Participants' remit $(\mathbf{n}=54)$

\begin{tabular}{lccc}
\hline & Kenya & Turkey & Brazil \\
\hline & & & $8^{*}$ \\
Teacher & 4 & 1 & $\mathrm{x}$ \\
Counsellor & 4 & 1 & $\mathrm{x}$ \\
Counselling Teacher & 3 & 1 & $\mathrm{x}$ \\
Academic & 3 & 1 & 4 \\
NGO Manager / & 2 & 2 & \\
Co-Ordinator & & & 3 \\
Volunteer & $\mathrm{X}$ & 3 & $\mathrm{x}$ \\
Lawyer & 2 & $\mathrm{X}$ & $\mathrm{X}$ \\
Police Officer & 3 & $\mathrm{X}$ & $\mathrm{X}$ \\
Pastor/Religious Leader & 3 & 1 & $\mathrm{X}$ \\
Health Worker/Doctor & 1 & 2 & $\mathrm{x}$ \\
Psychologist & 1 & $\mathrm{X}$ & 15 \\
Parent & 1 & 12 & \\
\hline Total & 27 & & \\
\hline
\end{tabular}

*3 teachers, 2 head teachers (1 mainstream school and 1 kindergarten), 1 teacher/antiviolence educator, 1 civil rights educator, 1 teacher student 
Table 2

Mapping analysis and action plans categories along the six framework domains

\section{Mapping}

Vision

Promoting children's rights and safety

Well-being and psychological resilience

Awareness and empowerment

Service improvement

Participants' roles

Knowledge of territory

Protection and empowerment

Therapeutic skills

Education and interventions

Current resources

Human resources

Community groups

Agencies (statutory and NGOs)

\section{Action plans}

Safety and child-centeredness

Improving physical and emotional safety

Increasing awareness

Supporting policy and legislation

Skills in communication and recognition

Quality of care

Psychoeducation

Family engagement and mobilization

Support groups for caregivers

Building resilience through school and community

Raising awareness in the community through public and religious institutions

Improving functionality of environments

Educational policies

Inter-agency working

Enhancing skills of universal practitioners and communities

Continuing training on impact of trauma and symptom recognition

Staff retention

Targeted to vulnerable groups (e.g. refugee or minorities)

Community skills

Counselling and psychological interventions

Demystification through awareness

Professionalization

Integration with other services

Access to child mental health services

Joint care pathways

Inter-sector working

Family engagement

Resource allocation 


\section{Figure 1}

\section{(Anonymized) child psychosocial framework}

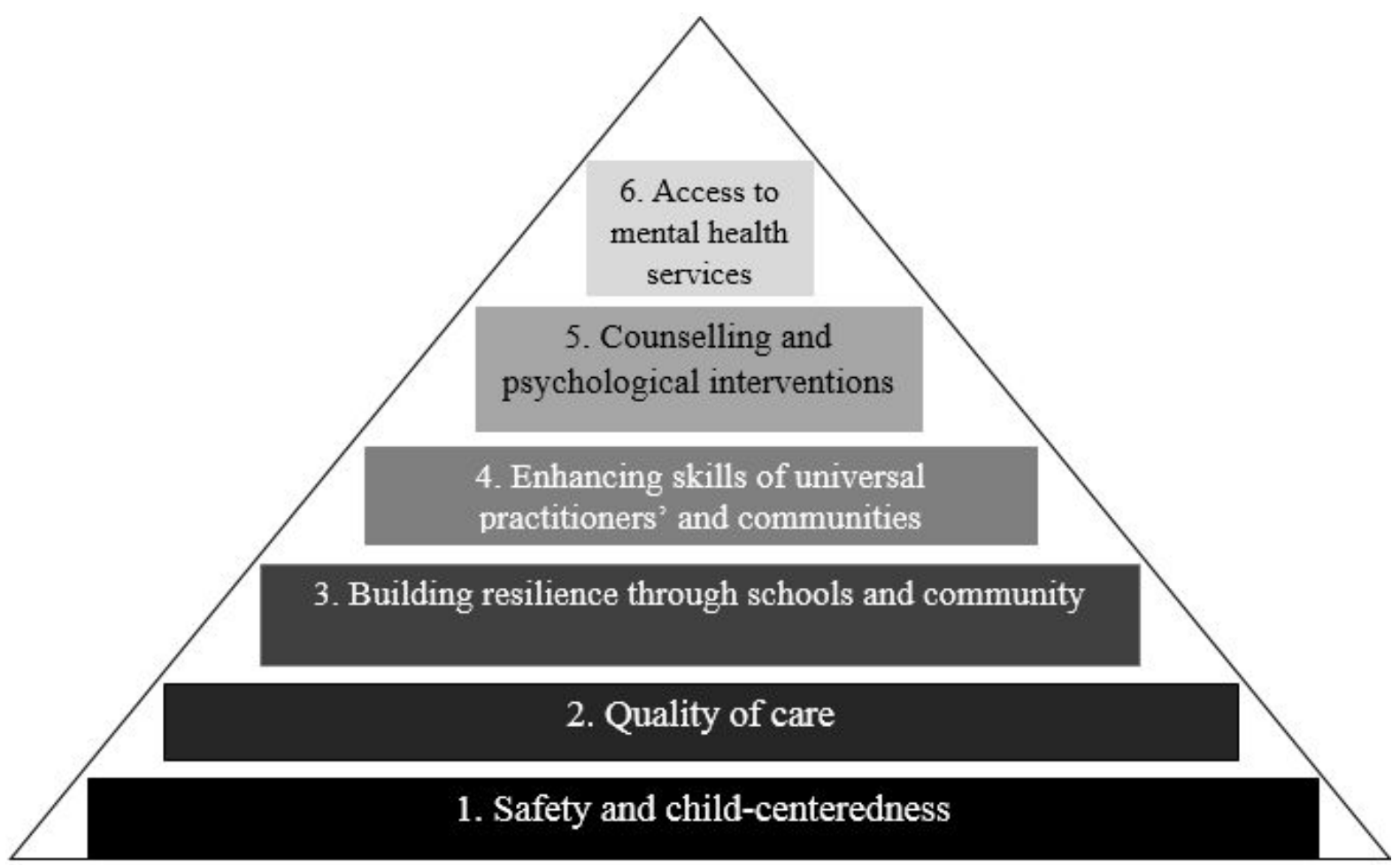


Figure 2

Final thematic template

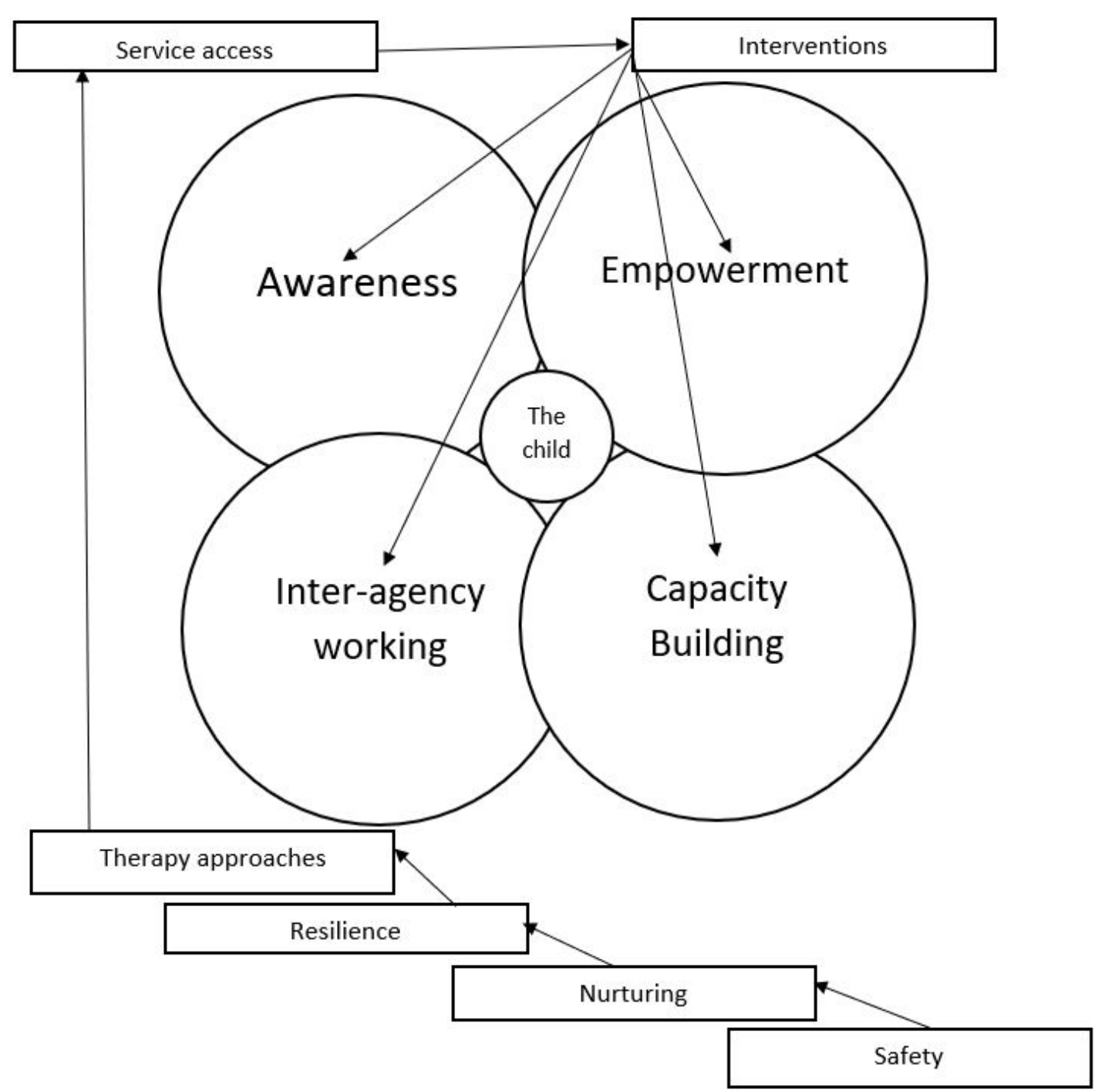


Journal of Children's Services

Page 42 of 42

Image 1

Flipchart material from Kenya workshop

CHIS MENTAL HEALTH SERVICES 1. hap \& barriers

- Lack of mental faculties for cheldion.

- Stigmatization ffabods

- Lack of awareness.

- Lack of skills on child mental hearth.

- Lack of poetical good will Lmumanggemes af Jun a

2. Capacities's \& strengths.

- special schools

- Health jacilites

3. priontiles

- Creating Health instructions (mental).

- Budget allocations (proper).

4. Action plan.

- cromingop more jaciuties for mental health. VIC

- Community mobil lizatión.

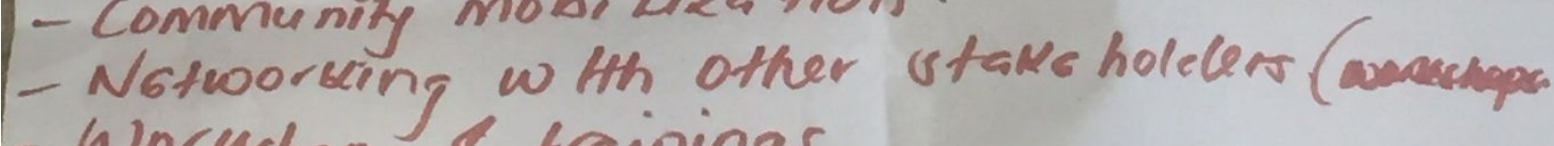

- Workshops \& trainings

- pouticar influencing Jor funds. 